\title{
Does coffee drinking increase the risk of coronary heart disease? Results from a meta-analysis
}

\author{
Ichiro Kawachi, Graham A Colditz, Catherine B Stone
}

\begin{abstract}
Background-The association between coffee drinking and risk of coronary heart disease remains controversial despite many epidemiological studies. A metaanalysis was carried out on these studies to resolve some of the uncertainties. Particular attention was paid to details of study design.
\end{abstract}

Methods-Eight case-control studies and 15 cohort studies were analysed. Weighted, fixed effects linear regression of $10 g$ relative risks (or odds ratios) was used to pool the study results. The pooling procedures were performed separately by study design, sex, coronary heart disease end points, smoking habit, and period of study.

Results-The pooled case-control odds ratio (for the effect of drinking five cups of coffee/day $v$ none) was $1.63(95 \%$ confidence interval (95\% CI) 1.50 to $1 \cdot 78)$. The pooled cohort study relative risk (five cups/day $v$ none) was 1.05 (95\% CI 0.99 to 1.12). The discrepancy between the pooled case-control and cohort study results could not be attributed to differences in the end points chosen, period of study, or to confounding by smoking status or sex.

Conclusions-The cohort study data suggest very little excess risk of coronary heart disease among habitual coffee drinkers. The case-control data do not rule out an increased risk of heart disease among a subgroup of people who acutely increase their coffee intake. Further epidemiological studies are needed to assess the risk of drinking boiled or decaffeinated coffee.

(Br Heart f 1994;72:269-275)

The association between coffee drinking and risk of coronary heart disease (CHD) remains controversial despite many epidemiological studies. A relation of coffee drinking to CHD was first suspected because of the role of caffeine in inducing cardiac arrhythmias, and increases in plasma renin activity, catecholamine concentrations, and blood pressure. ${ }^{12}$ Although it seems now that these effects are not clinically significant in most habitual drinkers, ${ }^{3}$ renewed concern has arisen from cross sectional findings of an association between coffee drinking and serum total cholesterol concentrations. ${ }^{4-9}$

The inconsistent findings of epidemiological studies-for example, comparing the results of LaCroix et $a l^{10}$ with those of Grobbee et $a l^{11}$-have resulted in conflicting policy advice. ${ }^{12}$ To resolve some of the existing uncertainties, we applied the techniques of meta-analysis to all published epidemiological studies of coffee consumption and CHD, paying particular attention to details of study design.

\section{Patients and methods}

METHODS

Selection of studies

Epidemiological studies of coffee consumption and heart disease were identified by a computer aided literature search, as well as by bibliographical searches of review articles ${ }^{13}$ and previous meta-analysis. ${ }^{12} 14$

Early case-control studies ${ }^{15-17}$ were excluded from the meta-analysis as these reports included insufficient information to permit calculations of relative risks and SEMs. Two studies ${ }^{18} 19$ were excluded on the basis that they examined prevalence of heart disease only. Wherever more than one published report was generated with the same cohort or case-control study, ${ }^{20-23}$ the most updated data were included in the metaanalysis. ${ }^{24-27}$ In the case of the Framingham study the original report by Dawber et $a l^{8}$ examined non-fatal myocardial infarction as an end point, whereas the update of the same cohort $^{29}$ provided data on total cardiovascular disease mortality (including angina, congestive heart failure, and intermittent claudication). We used the more recent Framingham data $^{29}$ in the overall pooled analysis, although we included the earlier report ${ }^{28}$ in a subanalysis of studies that used myocardial infarction as an end point. Similarly, in the case of the Seventh Day Adventists' cohort, the original report by Snowdon et $a l^{23}$ assessed fatal CHD in men and women, whereas the updated report ${ }^{27}$ presented data for men only. We used the more recent data $^{27}$ in the overall pooled analysis, but included the earlier report ${ }^{23}$ subanalyses broken down by sex. A total of eight case-control studies ${ }^{25}$ 30-37 (appendix 1) 
and 15 cohort studies 101124262729 37-45 (appendix 2) were used in the meta-analysis.

\section{Statistical methods}

The pooled method involved a weighted, fixed effects linear regression of the log relative risks (or odds ratios) from the individual studies, with the inverse of the variance of $l o g$ relative risks as the weights. To convert $95 \%$ confidence intervals (95\% CIs) into estimates of the variance of the log relative risk (or odds ratio), we transformed the interval to the log scale. The absolute difference between the upper and lower end points was then divided by 3.92 to obtain an approximate SEM. The procedure was modified in reports that gave $90 \%$ CIs. ${ }^{46}$ Where the original studies provided no SEMs or CIs for rates or relative risks, these were estimated with procedures described by Greenland. ${ }^{14}$ The weighted linear regressions were performed in SAS. ${ }^{47}$ As noted by Greenland, ${ }^{14}$ the SEMs computed by this program needed to be corrected by dividing the printed SEMs by the square root of the residual mean square.

\section{Assignment of exposures}

Virtually all the studies reported coffee consumption as categories - for example, two to four cups/day, more than five cups/day. We assigned category midpoints to each category. For open ended categories, we used Greenland's suggestion ${ }^{14}$ and assigned the mean number of cups/day for a particular category based on the distribution of coffee consumption reported in the Framingham study. ${ }^{28}$ Thus we assigned 6.5 cups for the category five or more cups/day; 7.4 cups for the category six or more cups/day; 8.5 cups for the category seven or more cups/day; nine cups for the category eight or more cups/day; and so on.

\section{Meta-analyses}

The meta-analyses were performed separately for case-control and cohort studies. The stud-

Table 1 Pooled odds ratios (ORs) and relative risks (RRs) (for the effect of drinking five cups/day $v$ none) from case-control studies and cohort studies of coffee consumption and CHD

\begin{tabular}{lcll}
\hline Type of study & No of studies & OR or $R R(95 \% C I)$ & $\chi^{2}$ for heterogeneity \\
\hline Case-control & 8 & OR $1.63(1.50$ to $1 \cdot 78)$ & 10.3 \\
Cohort & 15 & OR $1.66(1.52$ to 1.81$)$ & 85.4 \\
& & $\operatorname{RR}^{\star}{ }^{\star} 1.06(0.99$ to $1 \cdot 12)$ & 89 to 1.14$)$
\end{tabular}

* Effect of one cup/day $v$ none, under sensitivity analysis with conservative assignment of cups/day to open-ended categories (see methods).

Table 2 Pooled relative risks (RRs) (for the effect of five cups/day $v$ none) from cohort studies, broken down by $C H D$

\begin{tabular}{llll}
\hline End point & No of studies & $P R(95 \% C I)$ & $\chi^{2}$ for heterogeneity \\
\hline CHD death & 10 & $0.97 \star(0.04$ to 1.01$)$ & 66.2 \\
& 8 & $1.15+(1.10$ to 1.19$)$ & 32.7 \\
Myocardial infarction & 5 & $1.16(1.02$ to 1.30$)$ & 5.7 \\
Total CHD & 5 & $1.25(1.08$ to 1.46$)$ & 4.0 \\
\hline
\end{tabular}

* Including studies by Martin, et $a^{\mu 5}$ and Wilson et al. ${ }^{29}$

$\dagger$ Excluding studies by Martin, et $a^{45}$ and Wilson $e t \mathrm{a}^{29}$ that included data on non-CHD deaths, $\dagger$ Excluding studies by Martin, $e t$
such as congestive heart failure. ies used different end points of cardiovascular disease. For the overall pooled analysis, one end point was selected for each study. These were in order of priority: total CHD (fatal CHD and non-fatal myocardial infarction), myocardial infarction (fatal or non-fatal), or fatal CHD (including sudden coronary death). As well as the main pooled analysis, three separate meta-analyses of cohort studies were carried out with CHD death, fatal or non-fatal myocardial infarction, and total $\mathrm{CHD}$ as end points. Studies that reported results for all three end points ${ }^{24}{ }^{40}$ contributed data to each subanalysis.

\section{Sensitivity analyses}

We examined the sensitivity of the pooled results to the method of assigning cups/day to the open ended categories used for the highest intake of coffee. In this sensitivity analysis, we assigned the lowest number of cups in a particular category instead of the mean number of cups based on the Framingham distribution. Thus we assigned six cups to the category six or more cups/day (instead of $7 \cdot 4$ cups), and seven cups to the category seven or more cups/day (instead of 8.5 cups).

Two studies reported on total cardiovascular disease events rather than coronary heart disease events. ${ }^{29} 45$ The pooled analyses were repeated both including and excluding these two studies to examine the sensitivity of the results of studies with different end points.

As cigarette smoking is positively associated with coffee consumption, ${ }^{4849}$ failure to adjust for smoking results in a biased estimate of the risk of coronary heart disease. In our study, we performed a meta-analysis restricted to non-smokers, with data from a subsample of studies that reported data separately for smokers and non-smokers.

We next carried out a pooled analysis of the three case-control studies 253234 that included data on decaffeinated coffee. Only one cohort study provided data on decaffeinated coffee intake. ${ }^{11}$ We also carried out separate analyses for men and women to look for any sex differences in the effect of coffee on heart disease.

\section{Results}

GENERAL FINDINGS

Appendices to tables 1 and 2 show the characteristics of the case-control and cohort studies included in the meta-analysis. Of the eight case-control studies selected for metaanalysis, seven 25 30 32-35 37 reported a positive association (or a significant trend in risk) between coffee consumption and coronary heart disease. Of the 15 cohort studies included in the meta-analysis, five 1026273942 reported a positive association between coffee intake and risk of heart disease.

\section{REGRESSION RESULTS}

Unless otherwise stated, all the pooled odds ratios (or relative risks) given are for the comparison of five cups of coffee/day $v$ none. A log linear assumption was made, in which the 
estimated relative risk for five cups/day is the antilog of five times the coefficient for one cup ( $v$ none) shown on appendices to tables 1 and 2.

The pooled odds ratio for case-control studies was 1.63 (95\% CI 1.50 to 1.78$)$. The $\chi^{2}$ for heterogeneity among case-control studies was 10.3 (degrees of freedom (df) 7 , $P>0 \cdot 1$ ). For cohort studies, the pooled relative risk was 1.05 (95\% CI 0.99 to 1.12$)$. Due to the extremely high heterogeneity among the cohort studies $\left(\chi^{2}=85 \cdot 4\right.$, df 14 , $P<0.0001$ ), the SEM for the pooled coefficients is almost certainly an underestimate. When the regression procedures were repeated with the more conservative assignment of cups/day in the open ended categories, the pooled odds ratios or relative risks were virtually unchanged (table 1 ).

We carried out separate pooled procedures for each of the end points: CHD death, myocardial infarction (fatal and non-fatal), and total CHD (table 2). These analyses were done only for cohort studies, as all the casecontrol studies used myocardial infarction as their end point (with the exception of the study by Hennekens et al, ${ }^{36}$ which used fatal $\mathrm{CHD}$ as the end point). The pooled relative risks were $0.97(95 \% \mathrm{CI} 0.94-1 \cdot 01)$ for $\mathrm{CHD}$ death, $1.16(95 \%$ CI 1.02 to 1.30$)$ for myocardial infarction, and $1.25(95 \% \mathrm{CI}$ 1.08 to 1.46 ) for total CHD. These results suggest a possible slight increase in risk of coronary heart disease, although the magnitude of the effect is such that confounding for example, by smoking - could not be ruled out.

To compensate for confounding by smoking we next performed a pooled analysis restricted to data on non-smokers. Three case-control studies, ${ }^{25} 3435$ and six cohort studies $^{263739404245}$ included such data (table 3). Among cohort studies there was no suggestion of increased risk (pooled relative risk $=$ $1.04 ; 95 \%$ CI 0.71 to 1.52$)$. The pooled result among case-control studies was again discrepant from the cohort data with a summary odds ratio among non-smokers of 1.85 (95\% CI 1.42 to $2 \cdot 42$ ).

The pooled odds ratio from the three case-

Table 3 Pooled odds ratios (ORs) and relative risks (RRs) (for the effect of five cups/day $v$ none) from case-control and cohort studies of coffee consumption and CHD, restricted to non-smokers

\begin{tabular}{lllc}
\hline Type of study & No of studies & OR or $R R(95 \%$ CI $)$ & $\chi^{2}$ for heterogeneity \\
\hline Case-control & 3 & $1.85(1.42$ to 2.42$)$ & 7.2 \\
Cohort & 6 & $1.04(0.71$ to 1.52$)$ & 11.2 \\
\hline
\end{tabular}

Table 4 Pooled odds ratios (ORs) and relative risks (RRs) (for the effect of five cups $v$ none) from case-control studies and cohort studies of coffee consumption and CHD, by sex

\begin{tabular}{lccc}
\hline Type of study & No of studies & OR or RR $(95 \% \mathrm{CI})$ & $\chi^{2}$ for heterogeneity \\
\hline Case-control & & & \\
Men only & 3 & $1.69(1.50$ to 1.90$)$ & 4.3 \\
Women only & 3 & $1.54(1.33$ to 1.77$)$ & 2.6 \\
Men and women & 2 & $1.79(1.49$ to 2.14$)$ & 0.1 \\
Cohort: & 13 & $1.15(1.07$ to 1.25$)$ & 40.9 \\
Men only & 4 & $1.21(0.90$ to 1.63$)$ & 4.4 \\
Women only & 7 & $0.91(0.83$ to 0.99$)$ & 38.7 \\
Men and women & & & \\
\hline
\end{tabular}

control studies that examined decaffeinated coffee was $1.42\left(95 \%\right.$ CI 1.01 to $1.99, \chi^{2}$ for heterogeneity $=0 \cdot 9)$. This point estimate was not substantially different from the pooled odds ratio for caffeinated coffee (odds ratio $=$ $1 \cdot 65,95 \%$ CI 1.52 to $1 \cdot 81$ ).

We performed separate pooling procedures for men and women (table 4). The results for both case-control and cohort studies indicated similar magnitudes of effect of coffee drinking on risk of heart disease for men and women. The discrepancy between the results of case-control and cohort studies persisted.

\section{Discussion}

Our meta-analysis supersedes previous studies $^{1214}$ because it includes case-control studies (omitted in the study of Myers and Basinski ${ }^{12}$ ); pools data from a more comprehensive set of studies (15 cohort studies compared with 11 analysed in Myers and Basinski, ${ }^{12}$ and five by Greenland ${ }^{14}$ ); and stratifies the analyses by disease end point, smoking, and sex.

\section{ASSESSMENT OF CAUSALITY}

Bradford Hill proposed a set of criteria by which to assess causality-namely, the strength, consistency, and specificity of the association found, the time relation between exposure and outcome, the existence of a biological gradient, and biological plausibility. ${ }^{50}$ We consider each of these in turn.

\section{Strength of association}

The pooled cohort study data suggest, at most, a very weak association (relative risk < 1.2) between coffee intake and risk of CHD. Even the pooled case-control data do not suggest a relative risk of $\mathrm{CHD}$ greater than about 1.6 for drinking five or more cups/day. Relative risks of this magnitude could easily arise from residual confounding by factors such as smoking, diet, and other cardiovascular risk factors. ${ }^{50}$ Coffee drinkers are more likely to smoke than those who do not drink coffee. ${ }^{4849}$ Failure to adjust for cigarette smoking may thus lead to spurious associations between coffee drinking and CHD. Among studies that adjusted for smoking, sometimes substantial differences have been found between the crude age adjusted relative risks and the multivariate relative risks. For example, in the study by LaVecchia et $a l^{32}$ the age adjusted odds ratio for drinking four or more cups/day was $2.65(95 \%$ CI 1.56 to 4.52 ) compared with 1.72 ( $95 \%$ CI 0.92 to 3.23) after adjustment for smoking and a range of other CHD risk factors.

Some of the earlier case-control studies that reported a positive association between coffee intake and CHD did not control for smoking-for example, those of Jick et $a l^{30}$ the Boston collaborative drug surveillance program, ${ }^{35}$ and Mann and Thorogood. ${ }^{33}$ Alternatively, failure to control for smoking cannot entirely account for the discrepancy between the pooled case-control and cohort study results, as the analyses restricted to data 
on non-smokers continued to show an excess risk among case-control studies (pooled odds ratio $=1.85,95 \% \mathrm{CI} 1.42$ to 2.42 ) but no increased risk among cohort studies (pooled risk ratio $=1 \cdot 04,95 \% \mathrm{CI} 0.71$ to $1 \cdot 52$ ).

\section{Consistency of the association}

The cohort studies included in our metaanalysis were consistent in suggesting a lack of (or, at most, a very weak) association between coffee intake and risk of coronary heart disease. By contrast, the case-control studies consistently pointed to an excess risk. Among the possible explanations for this discrepancy is that some earlier hospital based case-control studies included patients among the controls who may have reduced their intake of coffee after a diagnosis of chronic illness-for example, digestive diseases. ${ }^{30} 35$ Rosenberg et al examined the extent of this bias by including two types of control subjects in a hospital based case-control study: those admitted with acute emergencies and those with chronic diseases. ${ }^{20} 25$ Coffee intake was significantly lower among patients admitted to hospitals with chronic compared with acute conditions. Thus case-control studies that included control patients admitted for chronic conditions may have overestimated the association between coffee consumption and risk of heart disease. ${ }^{30} 35$

\section{Specificity of the association}

With one exception, ${ }^{36}$ all of the case-control studies used non-fatal myocardial infarction as the disease end point. By comparison, cohort studies looked at various end points, including non-fatal myocardial infarction, fatal $\mathrm{CHD}$, and angina. When we stratified the cohort data according to type of end point (table 2) there was no evidence to suggest that the effect of coffee drinking was specific to a particular category of CHD. Moreover, the discrepancy between the results of casecontrol studies and cohort studies could not be explained by differences in the choice of end points. The pooled odds ratio for casecontrol studies with myocardial infarction as the end point was 1.66 (95\% CI 1.52 to $1.81)$; whereas the pooled relative risk for cohort studies with myocardial infarction as the end point was $1.16(95 \%$ CI 1.02 to $1 \cdot 30)$.

Time relation between exposure and outcome

Retrospective ascertainment of exposure in case-control studies may pose a problem in the form of recall bias - that is, the experience of having had a coronary event selectively affects patients' recall of coffee consumption and smoking habit before the event. ${ }^{37}$ This problem is compounded by ascertainment of coffee intake by interviewers who were not blinded with respect to the case-control state of patients..$^{32} 323 \mathrm{In}$ theory, a prospective study design is more capable of making reliable assessments of both coffee intake and smoking habits.

Empirical evidence needs to be gathered to quantify the degree of recall bias, if any, in retrospective assessments of coffee intake. Data from cohort studies have shown the existence of recall bias when intake of other beverages (such as alcohol) are assessed retrospectively in relation to the onset of disease. ${ }^{51}$

One limitation of the prospective study design is the lag time between exposure assessment and outcome, which might potentially obscure acute effects of coffee intake on risk of heart disease. ${ }^{14}$ In cohort studies with repeated measurements of exposure assessment, the association between heart disease and coffee intake was strongest when the exposure measurement used was nearest to the outcome..$^{1042}$ In the study by LaCroix et al the relative risk for five or more cups/day compared with none increased from 1.8 (95\% CI 0.8 to 4.0 ) when intake was assessed 10 or more years previously, to 2.5 (95\% CI $1 \cdot 1$ to $5 \cdot 8$ ) when the intake within the past five years was used. ${ }^{10}$ Grobbee et al however, found no association between coffee intake and risk of heart disease, even though the mean lag time between exposure assessment and outcome was less than two years. ${ }^{11}$

Evidence from the Nurses' Health Study suggests that coffee intake in an individual subject stays stable over time..$^{52}$ In this study, which assessed the reproducibility of food and beverage intake nine months apart, the Spearman correlation coefficient for coffee intake was $0 \cdot 71$, the highest recorded of all the items in the diet.

\section{Biological gradient}

The case-control data consistently suggest a monotonic dose-response gradient between daily coffee intake and risk of myocardial infarction. Compared with non-drinkers, those who drink five or six cups of coffee have about double the risk of myocardial infarction (relative risks of $2 \cdot 2$ reported by Rosenberg $e t$ $a^{34} ; 2 \cdot 1$ by Rosenberg et $a l^{25} ; 2 \cdot 2$ by Jick et $a l ; 302 \cdot 1$ by the Boston collaborative drug surveillance program ${ }^{35}$; and 1.86 by Mann and Thorogood ${ }^{33}$ ). In contrast, there was no overall suggestion of a biological gradient in the cohort data. In their meta-analysis of 11 cohort studies Myers and Basinski reported relative risks of 1.01 among drinkers of one to four cups/day, 1.01 for four to six cups/day, and 1.09 for six or more cups/day (with drinkers of less than one cup/day as the reference category). ${ }^{12}$

\section{Biological plausibility}

The biological plausibility of the association between coffee drinking and CHD is based, in part, on the effects of caffeine on the cardiovascular system. The available evidence, however, fails to implicate caffeine as such as a significant contributor to risk of cardiovascular disease. ${ }^{3}$ Although the acute effects of caffeine on the cardiovascular system are well documented, it is doubtful that these are of sufficient clinical significance to produce CHD. Clinical data indicate that moderate caffeine consumption $(<500 \mathrm{mg} /$ dayequivalent to four to six cups of coffee) does not increase the frequency or severity of car- 
diac arrhythmias, even among people with ischaemic heart disease or patients with preexisting ventricular extrasystoles. ${ }^{53}$ Nor does regular ingestion of caffeine seem to lead to an increase in blood pressure (although infrequent use among people who have not developed tolerance does seem to cause a small, but clinically unimportant rise in blood pressure). ${ }^{354}$

Clinical trial evidence suggests that caffeine itself is unrelated to adverse effects on lipids. ${ }^{55}$ No studies to date have shown a positive association between tea intake and CHD even though tea contains caffeine (64 $\mathrm{mg} /$ cup of tea, compared with $136 \mathrm{mg} /$ cup for coffee). ${ }^{11} 303639$

Both the prospective data by Grobbee et $a l,{ }^{11}$ and a pooled analysis of the three casecontrol studies that included data on decaffeinated coffee, suggest a marginally increased risk of CHD with decaffeinated coffee consumption. In the study by Grobbee et al the relative risk of total CHD with four or more cups of decaffeinated coffee consumed/day was 1.63 (95\% CI 1.02 to 2.60$)$, which may be attributable to an adverse effect of decaffeinated coffee on serum lipids. ${ }^{11}$ In one randomised trial, the consumption of three to six cups of decaffeinated coffee/day raised the concentrations of low density lipoprotein cholesterol. ${ }^{57}$

\section{Boiled $v$ filtered coffee}

A biologically plausible hypothesis, not assessed by any of the epidemiological studies to date, is that the method of preparing coffee (boiling $v$ filtering) affects the risk of cardiovascular disease. In a meta-analysis of 21 cross sectional studies, Bak found that filtered coffee was associated with an average increase in total cholesterol of $0.008 \mathrm{mmol} / \mathrm{/} /$ daily cup consumed, compared with an increase of $0.038 \mathrm{mmol} / \mathrm{l}$ for boiled (unfiltered) coffee. ${ }^{54}$

The studies from Sweden ${ }^{40}$ and Norway ${ }^{42}$ present an interesting comparison in this regard. In Norway, boiled coffee is the most common form of preparation, whereas in Sweden the predominant method of preparation is filtration. The Norwegian study by Tverdal et al found relative risks of $\mathrm{CHD}$ death (comparing more than nine $v$ less than one cup/day) of $2 \cdot 2$ (95\% CI 1.1 to 4.5$)$ for men, and 5.1 (95\% CI 0.4 to 60.3$)$ for women. ${ }^{42}$ By contrast, the Swedish study reported a relative risk of CHD death (again comparing more than nine $v$ less than one cup/day) of $1.1(95 \%$ CI 0.5 to 2.4$)$ for men. ${ }^{40}$ (A Norwegian cohort study that found no association between coffee drinking and CHD death has also been reported. ${ }^{44}$ Unlike the study by Tverdal $e t a l^{42}$ this failed to exclude CHD cases at baseline; also, mortality data were obtained solely by linkage to the Norwegian Bureau of Statistics).

The adverse effect of coffee consumption on the lipid profile is now believed to stem from an as yet unidentified lipid soluble substance that is present in boiled preparations, but seems to be removed during the filtering process. ${ }^{58}$ Thus the precise measurement of coffee intake may be less relevant than the ascertainment of brewing method (filtered $v$ boiled) in future epidemiological investigations of coffee intake and CHD.

\section{Secular trends in coffee preparation method}

In the USA, there has been a considerable shift in the method of coffee preparation from percolated to filtered between 1975 and 1985. In $1975,75 \%$ of Americans drank percolated coffee and only $20 \%$ filtered, whereas by $1985,25 \%$ drank percolated coffee and $66 \%$ filtered (International Coffee Organization, 1989-quoted by $\left.\mathrm{Bak}^{54}\right)$. Percolation involves boiling coffee, which has been shown to have adverse effects on serum lipids. ${ }^{54}$

The secular trends in method of coffee preparation may be consistent with the generally positive associations between coffee intake and heart disease found in the United States case-control studies, all but one of which were completed during the 1970 sJick et al in $1972^{30}$; Boston collaborative drug surveillance program in 1972 ${ }^{35}$; and Rosenberg et al (female subjects) between 1976 and 1979..$^{25}$ Conversely, among cohort studies, there seems to be no consistent pattern whereby studies conducted before 1975 (the period during which there was relatively high prevalence of percolated coffee consumption) show a positive association between coffee intake and heart disease. The seven studies completed before 1975 show no association between coffee drinking and heart disease (pooled relative risk $=1.03,95 \% \mathrm{CI}$ 0.94 to 1.12 ); whereas the four studies that assessed coffee drinking during the 1980s reported a slightly positive association (pooled relative risk $=1.21,95 \%$ CI 1.05 to 1.40).

In conclusion the pooled cohort data suggest very little association between coffee intake and risk of CHD. The pooled casecontrol data suggest an excess risk of the order of $60 \%$ for drinking five cups/day. The higher risk estimates from individual casecontrol studies may have resulted from a combination of bias in control selection ${ }^{3035}$; recall bias; or be confounded by cigarette smoking $^{3033} 35$; although it is unlikely that the discrepancy between cohort and case-control data could be wholly explained by bias ana confounding. It is possible that cohort studies may have missed an acute effect of coffee drinking on CHD risk, although the evidence for this hypothesis is sparse and inconsistent. Further studies are needed to assess the risk of drinking boiled coffee and decaffeinated coffee, as there are biologically plausible reasons to hypothesise an association with CHD.

Preparation of this report was supported in part by the National Coffee Association. IK was the recipient of an overseas research fellowship of the Health Research Council of New Zealand during the early stages of this study.

1 Robertson D, Frohlich JC, Carr RK, et al. Effects of caffeine on plasma renin activity, catecholamines, and blood pressure. $N$ Engl $\mathcal{F}$ Med 1978;298:181-6.

2 Dobmeyer DJ, Stine RA, Leier CV, et al. The arrhythmogenic effects of caffeine in human beings. $N \mathrm{Engl} \mathcal{f} \mathrm{Med}$ 1983;308:814-5.

3 Myers MG. Cardiovascular effects of caffeine. Can Fam Physician 1992;38:1459-62. 
4 Thelle DS, Arnesen E, Forde OH. The Tromso heart study: does coffee raise serum cholesterol? $N$ Engl f Med 1983;308:1454-7.

5 Kark JD, Friedlander Y, Kaufman NA, et al. Coffee, tea and plasma cholesterol: the Jerusalem lipid research clinic prevalence study. BMF 1985;291:699-703

6 Curb JD, Reed DM, Kautz JA, et al. Coffee, caffeine, and serum cholesterol in Japanese men in Hawaii. Am $\mathfrak{F}$ Epidemiol 1986;123:648-55.

7 Mathias S, Garland C, Barrett-Connor E, et al. Coffee, plasma cholesterol and lipoproteins: a population study in an adult community. Am $f$ Epidemiol 1985;121: 896-905.

8 Williams PT, Wood PD, Vranizan KM, et al. Coffee intake and elevated cholesterol and apolipoprotein $B$ levels in men. $¥ A M A$ 1985;253:1407-11.

9 Coffee and cholesterol. Lancet 1985;i:1283-4.

10 LaCroix AZ, Mead LA, Laing KY, et al. Coffee consumption and the incidence of coronary heart disease. $N$ Engl tion and the incidence of

11 Grobbee DE, Rimm EB, Giovannucci E, et al. Coffee caffeine, and cardiovascular disease in men. $N$ Engl $\mathcal{F}$ Med 1990,323:1026-32.

12 Myers MG, Basinski A. Coffee and coronary heart disease. Arch Intern Med 1992;152:1767-72.

13 Christensen L, Murray T. A review of the relationship between coffee consumption and coronary heart disease. f Community Health 1990;15:391-408.

14 Greenland S. Quantitative methods in review of epidemiologic literature. Epidemiol Rev 1987;9:1-30.

15 Brown A. Coronary thrombosis: an environmental study. $B M F$ 1962;2:567-73.

16 Yudkin J, Roddy J. Levels of dietary sucrose in patients with occlusive atherosclerotic disease. Lancet 1964;ii. 6-8.

17 Little JA, Shanoff HM, Csima A, et al. Diet and serum lipids in male survivors of myocardial infarction. Lancet 1965;1:933-5.

18 Hrubec $Z$. Coffee drinking and ischaemic heart disease. Lancet 1973;i:548.

19 Howell RW, Wilson DG. Dietary sugar and ischaemic heart disease. $B M \mathcal{F}$ 1969;iii: 145-8.

20 Rosenberg L, Slone D, Shapiro S, et al. Coffee drinkin and myocardial infarction in young women. $\mathrm{Am}$ Epidemiol 1980;111:675-81.

21 Yano K, Rhoads GG, Kagan A. Coffee, alcohol and risk of coronary heart disease among Japanese men living in Hawaii. N Engl f Med 1977;297:405-9.

22 Paul $O$. Stimulants and coronaries. Postgrad Med 1968;44:196-9.

23 Snowdon DA, Phillips RL, Fraser GE. Meat consumption and fatal ischemic heart disease. Prev Med 1984;13: $490-500$

24 Yano K, Reed DM, MacLean CJ. Letter to the editor. $N$ Engl f Med 1987;316:946.

25 Rosenberg L, Werler MM, Kaufman DW, et al. Coffe drinking and myocardial infarction in young women: a update. Am f Epidemiol 1987;128:147-9.

26 LeGrady D, Dyer AR, Shekelle RB, et al. Coffee consumption and mortality in the Chicago Western Electric Company Study. Am $\mathcal{F}$ Epidemiol 1987;126:803-12.

27 Lindsted KD, Kuzma JW, Anderson JL. Coffee consumption and cause-specific mortality. Association with age death and compression of mortality. $f$ Clin Epidemiol 1992;45:733-42.

28 Dawber TR, Kannel WB, Gordon T. Coffee and cardiovascular disease. N Engl f Med 1974;291:871-4.

29 Wilson PWF, Garrison RJ, Kannel WB, McGee DL, Castelli WP. Is coffee consumption a contributor to carCastelli WP. Is coffee consumption a contributor to car-

30 Jick H, Miettinen OS, Neff RK, et al. Coffee and myocardial infarction. $N$ Engl $\mathcal{F}$ Med 1973;289:63-7.

31 Jick H. Re: coffee and myocardial infarction [letter]. $\mathrm{Am}$ f Epidemiol 1981;113:103-4

32 LaVecchia C, Gentile A, Negri E, et al. Coffee consumption and myocardial infarction in women. $A m$ f Epidemiol 1989;130:481-5.

33 Mann JI, Thorogood M. Coffee-drinking and myocardial infarction. Lancet 1975;ii:1215.
34 Rosenberg L, Palmer JR, Kelly JP, et al. Coffee drinking and nonfatal myocardial infarction in men under 55 years of age. Am $\mathcal{F}$ Epidemiol 1988;128:570-8.

35 Boston collaborative drug surveillance program. Coffee drinking and acute myocardial infarction. Lancet 1972. ii: $1278-81$.

36 Hennekens $\mathrm{CH}$, Drolette MJ, Jesse MJ, et al. Coffee drinking and death due to coronary heart disease. $N$ Engl F Med 1976;294:633-6.

37 Wilhelmsen L, Tibblin G, Elmfeldt D, et al. Coffee consumption and coronary heart disease in middle-aged Swedish men. Acta Med Scand 1977;201:547-52.

38 Klatsky AL, Friedman GD, Siegelaub AB. Coffee drinking prior to acute myocardial infarction. $\mathscr{F} A M A$ 1973;226:540-3

39 Klatsky AL, Friedman GD, Armstrong MA. Coffee use prior to myocardial infarction restudied: heavier intake may increase risk. Am 7 Epidemiol 1990;132:479-88.

40 Rosengren A, Wilhelmsen L. Coffee, coronary heart disease and mortality in middle-aged Swedish men: findease and mortality in middle-aged Swedish men: findings from the p

41 Murray SS, Bjelke E, Gibson RW, et al. Coffee consumption and mortality from ischemic heart disease and othe causes: results from the Lutheran Brotherhood study. Am $\mathcal{F}$ Epidemiol 1981;113:661-7.

42 Tverdal A, Stensvold I, Solvoll K, et al. Coffee consumption and death from coronary heart disease in middleaged Norwegian men and women. BMF 1990;300: 566-9.

43 Heyden S, Tyroler HA, Heiss G, et al. Coffee consumption and total mortality. Arch Intern Med 1978;138:1472-5.

44 Jacobsen BK, Bjelke E, Kvale G, Heuch I. Coffee drinking, mortality, and cancer incidence: results from a Norwegian prospective study. $¥$ Natl Cancer Inst 1986; 76:823-31.

45 Martin JB, Annegers JF, Curb JD, et al. Mortality among hypertensives by reported level of caffeine consumption.

46 Berlin JA, Colditz GA. A meta-analysis of physical activity in the prevention of coronary heart disease. $A m$ Epidemiol 1990;132:612-28.

47 SAS Institute Inc. SAS guide for personal computers. Cary, NC: SAS Institute, 1985

48 Puccio EM, McPhillips JB, Barrett-Connor E, Ganiats TG. Clustering of atherogenic behaviours in coffe drinkers. Am f Public Health 1990;80:1310-3.

49 Jacobsen BK, Thelle DS. The Tromso heart study: is coffee drinking an indicator of a life style with high risk for ischemic heart disease? Acta Med Scand 1987;222: 215-21.

50 Bradford Hill A. $A$ short textbook of medical statistics, 11 th ed. London: Hodder and Stoughton, 1984:272-7.

51 Giovannucci E, Stampfer MJ, Colditz GA, et al. A comparison of prospective and retrospective assessments of diet in the study of breast cancer. Am $\mathcal{F}$ Epidemio 1993;137:502-12.

52 Colditz GA, Willett WC, Stampfer MJ, Sampson L Rosner B, Hennekens CH, Speizer FE. The influence of age, relative weight, smoking, and alcohol intake on the reproducibility of a dietary questionnaire. Int 7 Epidemiol 1987;16:392-8.

53 Myers MG. Caffeine and cardiac arrhythmias. Ann Intern Med 1991;114:147-50.

54 Bak AAA. Coffee and cardiovascular risk: an epidemiolog ical study. Rotterdam: Erasmus University, 1990. (PhD thesis.)

55 Bak AAA, Grobbee DE. Caffeine, blood pressure, and serum lipids. Am $\mathcal{F}$ Clin Nutr 1991;53:971-5

56 Fried RE, Levine DM, Kwiterovich PO, Diamond EI Wilder LB, Moy TF, Pearson TA. The effect of filteredcoffee consumption on plasma lipid levels. Results of randomized clinical trial. $\mathcal{F A M A}$ 1992;267:811-5.

57 Superko HR, Bortz W, Albers J, Wood PD. Lipoprotei and apolipoprotein changes during a controlled trial of caffeinated and decaffeinated coffee drinking in men. Circulation 1989;80 (suppl II):II-86.

58 Thelle DS. Coffee and cholesterol: what is brewing? f Intern Med 1991;230:289-91.

Appendix 1: Summarised characteristics of the case-control studies used in the meta-analysis

\begin{tabular}{|c|c|c|c|c|}
\hline Author & No cases (sex/age) & Outcomes & Coefficient (SEM)* & Adjustments \\
\hline Jick, et $a l^{30}$ & $440(M+F / 20-75)$ & $\mathrm{MI}$ & $0 \cdot 120(0.022)$ & Age, sex \\
\hline LaVecchia, et al ${ }^{32}$ & $262(\mathrm{~F} / 24-69)$ & MI & $0.061(0.048)$ & $\begin{array}{l}\text { Age, sex DM, BP, CHOL, } \\
\text { DM, ALC, BMI, other }\end{array}$ \\
\hline Rosenberg, et al ${ }^{2025}$ & $491(\mathrm{~F} / 30-44)$ & MI & $0.068(0.021)$ & $\begin{array}{l}\text { Age, SMK, DM, BP, CHOL, } \\
\text { BMI, other }\end{array}$ \\
\hline Mann and Thorogood 33 & $64(\mathrm{~F} /<45)$ & MI & $0.0001(0.070)$ & Age \\
\hline Rosenberg, et $a l^{34}$ & $1,867(M /<55)$ & MI & $0.103(0.015)$ & $\begin{array}{l}\text { Age, SMK, DM, BP, } \\
\text { CHOL, BMI, ALC, other }\end{array}$ \\
\hline $\begin{array}{l}\text { Boston Collaborative Drug } \\
\text { Surveillance Program }\end{array}$ & $276(M+F)$ & MI & $0 \cdot 108(0 \cdot 032)$ & Age, sex \\
\hline Hennekens, et $a^{36}$ & $649(M / 30-70)$ & Fatal CHD & $0.030(0.043)$ & Age, SMK, BP, DM, other \\
\hline Wilhelmsen, et $a l^{37}$ & $230(M / 40-57)$ & MI & $0.131(0.023)$ & SMK, BP, CHOL, ALC \\
\hline
\end{tabular}

^ Coefficient for one cup $v$ none (SEM).

SMK, smoking; DM, diabetes mellitus; BP, blood pressure; CHOL, serum cholesterol concentration; BMI, body mass index; ALC, alcohol intake; MI, myocardial infarction. 
Appendix 2: Summarised characteristics of the cohort studies used in the meta-analysis

\begin{tabular}{|c|c|c|c|c|}
\hline Author & Cohort (sex/age) & Outcomes & Coefficient (SEM) * & Adjustments \\
\hline \multirow[t]{3}{*}{ Yan, et $a l^{21}$} & \multirow[t]{3}{*}{$7,705(M / 46-65)$} & MI & $0.016(0.039)$ & \multirow[t]{3}{*}{ Age, sex } \\
\hline & & CHD death & $0.049(0.070)$ & \\
\hline & & Total CHD & $0.058(0.026)$ & \\
\hline Wilhelmsen, et $a l^{37}$ & $834(\mathrm{M} / 50)$ & Total CHD & $0.113(0.153)$ & Age, sex, CHOL, BP, ALC \\
\hline Murray, et $a l^{41}$ & $16911(\mathrm{M} />35)$ & CHD death & $-0.008(0.017)$ & Age, SMK, other \\
\hline LaCroix, et $a l^{10}$ & $1130(\mathrm{M} / 19-49)$ & Total CHD & $0.103(0.043)$ & Age, SMK, BP, CHOL \\
\hline Jacobsen, et $a l^{44}$ & $16555(\mathbf{M}+\mathbf{F})$ & CHD death & $-0.023(0.016)$ & Age, sex \\
\hline LeGrady, et $a l^{26}$ & $1910(\mathrm{M} / 40-56)$ & CHD death & $0.119(0.031)$ & Age, SMK, BP, CHOL \\
\hline Martin, et $a l^{45}$ & $10064(M+F / 30-69)$ & Total CVD & $-0.051(0.40)$ & Age, sex, race \\
\hline Grobbee, et al ${ }^{11}$ & $45589(\mathrm{M} / 40-75)$ & Total CHD & $0.004(0.032)$ & $\begin{array}{l}\text { Age, SMK, BMI, ALC, } \\
\text { DIET, DM, other }\end{array}$ \\
\hline Tverdal, et $a l^{42}$ & $38564(M+F / 35-54)$ & CHD death & $0.104(0.055)$ & Age, SMK \\
\hline \multirow[t]{3}{*}{ Rosengren, Wilhelmsen ${ }^{40}$} & \multirow[t]{3}{*}{$6765(\mathrm{M} / 51-59)$} & MI & $0.050(0.036)$ & Age, SMK, BP, BMI \\
\hline & & CHD death & $0.010(0.042)$ & ALC, DM, other \\
\hline & & Total CHD & $0.035(0.030)$ & \\
\hline Lindsted, et $a^{27}$ & $9484(\mathrm{M} />30)$ & CHD death & $0.090(0.022)$ & SMK, BMI, BP, DIET, other \\
\hline Klatsky, et $a l^{38}$ & $464(M+F / 59)$ & MI & $-0.007(0.023)$ & $\begin{array}{l}\text { Age, sex, SMK, race, BP, } \\
\text { CHOL, other }\end{array}$ \\
\hline Klatsky, et $a l^{39}$ & $101774(M+F)$ & MI & $0.062(0.021)$ & $\begin{array}{l}\text { Age, sex, SMK, race, ALC, } \\
\text { other }\end{array}$ \\
\hline Wilson, et a $l^{29}$ & $6214(M+F / 30-67)$ & Total CHD & $-0.094(0.018)$ & Age \\
\hline Heyden, et $a l^{43}$ & $2530(M+F)$ & CHD death & $0.022(0.088)$ & Age \\
\hline
\end{tabular}

^ Coefficient for one cup $v$ none (SEM).

SMK, smoking; DM, diabetes mellitus; BP, blood pressure; CHOL, serum cholesterol concentration; BMI, body mass index; ALC, alcohol intake; MI, myocardial infarction. 